\title{
A Case of CANOMAD with Review of the Literature
}

\author{
Stephen Halpin ${ }^{1}$, Samer Al-Hussayni ${ }^{1}$, Sibte Hasan $^{2}$, Mark Busby ${ }^{3}$ and Rosaria Buccoliero ${ }^{{ }^{*}}$ \\ ${ }^{1}$ Department of Neurology, Harrogate District Foundation Trust, Harrogate, UK \\ ${ }^{2}$ Department of Neuroscience, York Teaching Hospital, York, UK \\ ${ }^{3}$ Department of Neurology, Bradford Teaching Hospitals NHS Trust, Bradford, UK \\ *Corresponding author: Rosaria Buccoliero, Harrogate District Hospital, Harrogate, HG2 7SX, UK, Tel: +44(0)1423 553038/4482; Fax: +44(0)1423553091; E-mail: \\ rosaria.buccoliero@hdft.nhs.uk
}

Rec date: Mar 06, 2015; Acc date: Apr 20, 2015; Pub date: Apr 22, 2015

Copyright: (C) 2015 Halpin S, et al. This is an open-access article distributed under the terms of the Creative Commons Attribution License, which permits unrestricted use, distribution, and reproduction in any medium, provided the original author and source are credited.

\begin{abstract}
Introduction: CANOMAD (an acronym for its full manifestation of chronic ataxic neuropathy, ophthalmoplegia, IgM paraprotein, cold agglutinins and disialosyl antibodies) is an uncommon paraproteinaemic neuropathy.

Methods and Results: We present the case of a man of 58 years at presentation, with chronic ataxic neuropathy, ophthalmoplegia, and an IgM paraprotein who was found to have antibodies active against disialosylgangliosides. Despite treatment trials with a range of immunosuppressive therapies, intravenous immunoglobulin proved the only effective treatment strategy in his case. Conclusions: CANOMAD has been described in a growing number of individual reports and small series for which we have methodically searched the literature. In the absence of randomised trials of treatment for this disabling condition, we bring together these published clinical experiences, describing the degree of heterogeneity in the presentation/laboratory findings and demonstrating that intravenous immunoglobulin is the therapy found most frequently to be successful.
\end{abstract}

Keywords: Gangliosides; Neuropathy; Paraproteinaemia

\section{Introduction}

The coexistence of a monoclonal paraprotein and neuropathy is not uncommon and is a feature of several distinct clinical syndromes [1]. A monoclonal IgM paraproteinaemic neuropathy in which IgM antibodies were found to react against disialosylgangliosides components of the human nervous system, was first described almost three decades ago [2]. Willison and colleagues in 1996 demonstrated in a rodent model that the antidisialosyl antibody itself exerted pathophysiological action on the peripheral nervous system and proposed the acronym CANOMAD to encompass the clinical features seen in this form of chronic neuropathy (chronic ataxic neuropathy, ophthalmoplegia, IgMparaprotein, cold agglutinins and disialosyl antibodies) [3]. A case series of 18 patients also published by Willison and colleagues provides one of the best descriptions available of the clinical and laboratory features of CANOMAD [4].

We describe a case of this rare neuropathy and our experience of multiple trialled treatments over an 11 year period. This is supplemented by description of several case reports gathered from the published literature, refining the observed phenotype and collating experiences of treatment.

\section{Case Report}

A 58 year old man presented to our Neurology outpatients department in 2001 with history of numbness in the hands and feet, imbalance, clumsiness of hands, lower limbs weakness and fluctuating double vision, which had progressed gradually over the course of one year. He was a long term smoker and had moderate alcohol consumption. On examination he used a walking stick, had a slightly unstable gait and a positive Romberg's sign. He reported diplopia on upward gaze, had mild left ptosis with no ophthalmoparesis, mild weakness of hip flexion and ankle dorsiflexion bilaterally. Muscle tone was normal and there were no cerebellar signs. Deep tendon reflexes were absent in upper and lower limbs and plantar responses were downgoing. He had diminished sense to light touch and pinprick modalities in the distal extremities and had impaired joint position sense and, most markedly, vibration sense in the feet. The initial clinical impression was most likely suggestive of chronic inflammatory demyelinating peripheral neuropathy.

Several investigations were organised on the basis of this clinical presentation. Full blood count, plasma viscosity, C-reactive protein and basic metabolic screen including blood glucose, thyroid function, vitamin $\mathrm{B} 12$ and folate that were normal. Antibodies to voltage-gated calcium channels and anti-acetylcholine receptors were negative. Creatine kinase was elevated at 507 iu/L (n.v. 40-320 iu/L). Serum protein electrophoresis and immunoglobulins levels were normal. The patient declined cerebrospinal fluid analysis. MRI scan of the brain and orbits and CT scan of thorax, abdomen and pelvis did not reveal any abnormalities.

Neurophysiological studies demonstrated poorly formed to absent sensory potentials and normal motor potentials without evidence of conduction block, though F-wave latencies were relatively prolonged. There was no evidence of neuromuscular junction disorder or myopathy. The neurophysiological findings were thought to reflect generalised axonal polyneuropathy of mild-moderate severity, predominantly affecting the sensory fibres but not consistent with sensory neuronopathy. Subsequently a sural nerve biopsy showed mild axonal degeneration, with a very sparse population of lymphocytic infiltration. Repeat neurophysiology 18 months later had not shown any significant change. 
Page 2 of 4

On balance he was treated as a case of Chronic Inflammatory Demyelinating Polyneuropathy (CIDP). Two years after the initial presentation, an exacerbation of gait ataxia prompted therapy with 60 $\mathrm{mg}$ oral prednisolone but without improvement. Second-line treatment with intravenous immunoglobulin (IVIg) was commenced, with a marked improvement in global symptoms and disability. There was no response to trials of azathioprine and methotrexate and ongoing IVIg was required.

Eight years after the initial presentation, development of skin lesions on the shins, characterised as leukocytoclastic cutaneous vasculitis on biopsy, prompted further investigations. A vasculitic screen including anti-nuclear antibodies, anti-neutrophil cytoplasmic antibodies, cryoglobulins, hepatitis $\mathrm{B}$ and $\mathrm{C}$ serology, rheumatoid factor, complement C3 and C4 were all negative. Repeating the serum protein electrophoresis at this point yielded a paraprotein band in the slow gamma region typed as IgM kappa. IgM levels were raised at 3.2 $\mathrm{g} / \mathrm{L}$ and $8 \mathrm{~g} / \mathrm{L}$ one year later. The finding of a large polyclonal IgG background with raised IgG levels was attributed to ongoing IVIg therapy. Cold agglutinins were negative. Antiganglioside antibody investigations revealed presence of IgM antibodies against GT1b and GD3 disialosylgangliosides. Other antiganglioside antibodies were absent. At this point a diagnosis of CANOMAD was made on the basis of the clinical, immunological and electrophysiological constellation.

Further immune modulating agents were trialled, with neither cyclophosphamide, mycophenolate nor the anti-CD20 monoclonal antibody rituximab achieving any improvement in symptoms or allowing sparing of IVIg. His neurophysiological parameters have gradually worsened with slow progression whereby at ten years after the initial presentation he had no recordable sensory potentials in his limbs, mildly slower motor conduction with evidence of conduction block with temporal dispersion in some nerves and electromyographic evidence of chronic neurogenic units in distal limb muscles.

IVIg has remained the mainstay of his management for 11 years, but it has been necessary over time to increase the frequency of the infusion cycle (from two-monthly to monthly, three weekly, then two weekly) due to the re-emergence of symptoms before the next infusion. Subjectively the patient gets a 'boost' from each infusion which lasts approximately a week then wanes. Attempts to reduce the dose have resulted in hospital admission with striking exacerbation of symptoms. Despite the good response to IVIg that allows the patient a decent quality of life his mobility has decreased over time and he is able to mobilise only with a zimmer frame.

\section{Literature Review}

Recognising that not all cases demonstrate all the features that make up the acronym CANOMAD, yet wishing to retain what seems to be a useful and genuine clinico-serological syndrome, Willison and colleagues suggest the simplest inclusive description that unites cases to be "a chronic sensory ataxic neuropathy with anti-disialosyl IgM antibodies" [4]. We therefore conducted a methodological search of the literature in January 2014, interrogating the databases MEDLINE, Embase, PsychINFO and CINAHL, with no restrictions made for language. Single case studies or case series were included if they described patients with chronic (or chronic relapsing) sensory ataxic neuropathy in the presence of anti-disialosyl IgM antibodies, where, as a minimum, basic demographics, the clinical presentation and the anti-ganglioside findings were available. Where the same case was reported in more than one publication, the most detailed was retained.

Twenty-six individual publications containing descriptions of 64 patients with chronic sensory ataxic neuropathy and anti-disialosyl IgM antibodies were found. This includes the largest case series of 18 patients [4], another series of 13 patients [5], 6 patients who were described within a larger series of 87 patients with neuropathy associated with monoclonal gammopathies [6] and two patients from a case series of 13 patients [7]. The remaining 22 publications are case reports of one or two patients with chronic sensory ataxic neuropathy and anti-disialosyl IgM antibodies [2,8-28].

\section{Demographics and clinical presentation}

The mean age at onset of symptoms was 55 years, and $75 \%$ were males. In $84 \%$ of cases the mode of onset was chronic; acute $(10 \%)$ and subacute $(7 \%)$ onsets being less frequently reported. Table 1 shows how frequently the main clinical features were reported to be present. The clinical syndrome included some sensory disturbance and gait ataxia in nearly every case, whilst there was motor involvement in less than half of cases. The most frequently seen cranial nerve involvement was weakness of the extraocular muscles. Areflexia was recorded in 39 cases, but the presence or absence of reflexes was not specified in the remaining 25 cases. "In four cases the paraproteinaemic neuropathy was coexistant with another specific pathology; one low grade B-cell non-Hodgkin's lymphoma [19], one diffuse large B-cell lymphoma [17], one extramembranous glomerulonephritis [14], and one syndrome of inappropriate anti-diuretic hormone secretion [15]."

\begin{tabular}{|l|l|l|l|l|l|l|l|}
\hline & $\begin{array}{l}\text { Cranial } \\
\text { nerves } \\
\text { III, IV, VI }\end{array}$ & $\begin{array}{l}\text { Cranial } \\
\text { nerve V }\end{array}$ & $\begin{array}{l}\text { Cranial } \\
\text { nerve VII }\end{array}$ & Bulbar & Paresis & $\begin{array}{l}\text { Sensory } \\
\text { disturbance }\end{array}$ \\
\hline $\begin{array}{l}\text { Number of cases reporting } \\
\text { feature to be present }\end{array}$ & 35 & 13 & 7 & 20 & 30 & 58 & 61 \\
\hline$\%$ (of 64 cases) & 55 & 20 & 11 & 31 & 47 & 91 & 95 \\
\hline
\end{tabular}

Table 1: Clinical features.

\section{Serological and neurophysiological findings}

All 64 cases by definition had IgM anti-disialosylganglioside antibodies. An IgM monoclonal paraprotein was identified in 47 cases $(73 \%)$ and typed in 44 cases as follows; $\kappa$ chain in $25(57 \%), \lambda$ chain in $16(36 \%)$ and both in $3(7 \%)$ of the cases. Serum IgM level was reported in 31 cases, being normal in 8 and raised in 23 . Of those with high levels the mean was $7.7 \mathrm{~g} / \mathrm{L}$ with a range of $2.8-20.5 \mathrm{~g} / \mathrm{L}$. Testing for cold agglutinins was reported in 44 cases and found to be positive in $21(48 \%)$ of these. 
Table 2 shows the frequency of identification of the most common IgM anti-ganglioside antibodie. In the 5 cases where GD1b was not found, 3 identified the presence of GQ1b antibodies, one had GD3 alone, and in the fifth both GD3 and GQ1b antibodies were found. In 32 cases all four of these antibodies were found. Less commonly occurring disialosylgangliosides, never identified alone, were GD1a (18 cases) and GD2 (4 cases). Thus, the antibodies are most frequently against b-series gangliosides, and in the majority of cases (52 out of 64, $81 \%$ ) activity against two or more b-series gangliosides was reported.

\begin{tabular}{|l|l|l|l|l|}
\hline \multicolumn{5}{|l|}{ IgM anti-ganglioside antibodies } \\
\hline & GD1b & GD3 & GT1b & GQ1b \\
\hline Present & 59 & 42 & 42 & 50 \\
\hline Absent & 5 & 13 & 14 & 10 \\
\hline $\begin{array}{l}\text { Not recorded } \\
\text { \% (present, out of total } \\
\text { of 64 cases) }\end{array}$ & 0 & 9 & 8 & 4 \\
\hline
\end{tabular}

Table 2: Number of clinical cases (and correspondent percentage) reporting the commonest anti-ganglioside findings.

Every case provided some report of the neurophysiological findings, and 15 cases included a sural nerve biopsy. The majority of cases showed a sensorimotor demyelinating peripheral neuropathy, with predominantly sensory involvement. There were however cases where sensory abnormalities were present alone and some demonstrating a mixed axonal and demyelinating pattern.

\section{Treatments}

In 42 published cases a report is given of the clinical experience of treatment of the syndrome. In total 12 different treatments were tried. The rates of success, temporary success and failure of the 5 most commonly used treatments, which were each used in at least 5 cases, are shown in Table 3. Since there were no standardised criteria across the published case reports of what constitutes treatment success, they were categorised as successful, temporarily successful or failed based on the available information. 'Successful' treatment included both narrative descriptions of improvement, full recovery or resolution of symptoms and objective measures, such as reduction in a numeric disability score. Treatments were judged 'temporarily successful' if the effect was described as transient or lasting up to 3 months. In 'failed' treatments there was either no response or a recognised worsening of symptoms on the treatment.

Less commonly tried therapies were methotrexate (failed in 3 cases), azathioprine (successful in 1 case, failed in 3), chlorambucil (successful in 2 cases, failed in 1), melphalan-prednisolone (successful in 1 case, failed in 1), infliximab (failed in 1 case), mycophenolate (failed in 1 case) and cyclophosphamide alone (successful in one case).

\begin{tabular}{|c|c|c|c|c|c|}
\hline & IVIg & Steroids & Plasmapheresis & Rituximab & $\begin{array}{l}\text { Cyclophosphamide } \\
\text { and prednisolone }\end{array}$ \\
\hline $\begin{array}{l}\text { Number } \\
\text { successful }\end{array}$ & 18 & 5 & 4 & 4 & 3 \\
\hline $\begin{array}{l}\text { Number } \\
\text { temporarily } \\
\text { successful }\end{array}$ & 3 & 0 & 1 & 0 & 0 \\
\hline Number failed & 10 & 11 & 5 & 1 & 2 \\
\hline $\begin{array}{l}\text { Total number of } \\
\text { cases treated }\end{array}$ & 31 & 16 & 10 & 5 & 5 \\
\hline
\end{tabular}

Table 3: Outcome of all treatments used in at least 5 cases. ${ }^{*}$ All cases reporting on use of cyclophosphamide and prednisolone in combination come from one publication.

\section{Discussion}

The case of CANOMAD we describe with the age at onset, male sex and chronic mode of onset is in many ways typical of the phenotype commonly found on our review of the literature. Gait ataxia and sensory disturbance were the most commonly reported clinical features and were also seen in our case. Serologically, whilst our finding of a kappa IgM paraprotein and antibodies against GT1b and GD3 was typical, the absence of GD1b antibodies was unusual, being the case in only $8 \%$ of previously published cases. Neurophysiological findings in our patient also revealed the preferential involvement of sensory nerves and gradually an emerging picture of demyelinating polyneuropathy.

Intravenous immunoglobulin is found to be the most commonly successful treatment in previous reported experience of managing
CANOMAD, and proved the only beneficial therapy in our case. Whilst rituximab was effective in 4 of the previous 5 reports, it offered no benefit for our patient.

The foundational case series of 18 patients described by Willison and colleagues in 2001 depicted a clinical presentation, which has undoubtedly further expanded when the other published studies and the experience in our patient are taken into consideration. It remains the case that the majority who present with CANOMAD are males in their 50's. However, cranial nerve involvement and motor symptoms were less common across all cases than originally described by Willison et al. Whilst 9 of the 18 patients $(50 \%)$ in their series had trigeminal involvement, this was reported in only 4 (9\%) of the other 46 cases we reviewed. Similarly, whilst 16 of the 18 patients (89\%) in that report had extraocular muscle weakness, some involvement of cranial nerves III, IV or VI was reported in only 19 (41\%) of the other 
46 cases. Sensory disturbance, conversely, was more frequently seen than indicated in the original case series; in 14 (77\%) of those 18 this was a feature, rising to $44(96 \%)$ of the other 46 cases reviewed. This analysis assumes that where a feature is not mentioned in a case report, it can be taken to have been absent. It is possible that some reports omitted minor symptoms.

\section{Conclusion}

Synthesising numerous case reports has limitations, significantly the lack of standardisation in reporting symptoms, clinical and laboratory findings and response to treatments. It is unknown how many cases of neuropathy with anti-disialosylganglioside IgM antibodies exist unrecognised or diagnosed with other names, perhaps with milder symptoms, leading to the possibility that only the most florid presentations are described in case reports. However, in the absence of larger, more robust studies and randomised controlled trials of treatment for this rare condition it is hoped that these collated experiences will assist in its identification and management.

\section{Acknowledgments}

The patient gave his informed written consent.

\section{References}

1. Rajabally YA (2011) Neuropathy and paraproteins: review of a complex association. Eur J Neurol 18: 1291-1298.

2. Ilyas AA, Quarles RH, Dalakas MC, Fishman PH, Brady RO (1985) Monoclonal IgM in a patient with paraproteinemic polyneuropathy binds to gangliosides containing disialosyl groups. Ann Neurol 18: 655-659.

3. Willison HJ, O'Hanlon GM, Paterson G, Veitch J, Wilson G, et al. (1996) A somatically mutated human antiganglioside IgM antibody that induces experimental neuropathy in mice is encoded by the variable region heavy chain gene, V1-18. J Clin Invest 97: 1155-1164.

4. Willison HJ, O'Leary CP, Veitch J, Blumhardt LD, Busby M, et al. (2001) The clinical and laboratory features of chronic sensory ataxic neuropathy with anti-disialosyl IgM antibodies. Brain 124: 1968-1977.

5. Attarian S, Boucraut J, Hubert AM, Uzenot D, Delmont E, et al. (2010) Chronic ataxic neuropathies associated with anti-GD1b IgM antibodies: response to IVIg therapy. J Neurol Neurosurg Psychiatry 81: 61-64.

6. Eurelings M, Ang CW, Notermans NC, Van Doorn PA, Jacobs BC, et al. (2001) Antiganglioside antibodies in polyneuropathy associated with monoclonal gammopathy. Neurology 57: 1909-1912.

7. Serrano-Munuera C, Rojas-García R, Gallardo E, De Luna N, Buenaventura I, et al. (2002) Antidisialosyl antibodies in chronic idiopathic ataxic neuropathy. J Neurol 249: 1525-1528.

8. Ahdab R, Lefaucheur JP, Malapert D, Touze E, Caudie C, et al. (2009) Neuropathy with anti-disialosyl IgM antibodies and multifocal persistent motor conduction blocks. J Neurol Neurosurg Psychiatry 80: 700-702.

9. Arai M, Yoshino H, Kusano Y, Yazaki Y, Ohnishi Y, et al. (1992) Ataxic polyneuropathy and anti-Pr2 IgM kappa M proteinemia. J Neurol 239: 147-151.

10. Arbogast SD, Khanna S, Koontz DW, Tomsak RL, Katirji B, et al. (2007) Chronic ataxic neuropathy mimicking dorsal midbrain syndrome. J Neurol Neurosurg Psychiatry 78: 1276-1277.
11. Barnett MH, Barnett Y, Burke D, Willison H (2011) Neurological picture. Spinal nerve root hypertrophy in chronic ataxic neuropathy with antiglycolipid IgM antibodies. J Neurol Neurosurg Psychiatry 82: 97.

12. Daune GC, Farrer RG, Dalakas MC, Quarles RH (1992) Sensory neuropathy associated with monoclonal immunoglobulin $\mathrm{M}$ to GD1b ganglioside. Ann Neurol 31: 683-685.

13. Delmont E, Jeandel PY, Hubert AM, Marcq L, Boucraut J, et al. (2010) Successful treatment with rituximab of one patient with CANOMAD neuropathy. J Neurol 257: 655-657.

14. Delval A, Stojkovic T, Vermersch P (2006) Relapsing sensorimotor neuropathy with ophthalmoplegia, antidisialosyl antibodies, and extramembranous glomerulonephritis. Muscle Nerve 33: 274-277.

15. Iorio R, Capone F, Iannaccone E, Willison HJ, Modoni A, et al. (2009) SIADH in a patient with sensory ataxic neuropathy with anti-disialosyl antibodies (CANOMAD). J Neurol 256: 1177-1179.

16. Kam C, Balaratnam MS, Purves A, Mills KR, Riordan-Eva P, et al. (2011) Canomad presenting without ophthalmoplegia and responding to intravenous immunoglobulin. Muscle Nerve 44: 829-833.

17. Kobayashi M, Kato K, Funakoshi K, Watanabe S, Toyoshima I (2005) Neuropathology of paraneoplastic neuropathy with anti-disialosyl antibody. Muscle Nerve 32: 216-222.

18. Löscher WN, Woertz A, Wallnöfer M, Wanschitz JV, Luef G (2013) Successful treatment of CANOMAD with IVIg and rituximab. J Neurol 260: 1168-1170.

19. Marfia GA, Pachatz C, Terracciano C, Leone G, Bernardini S, et al. (2005) Subacute demyelinating polyneuropathy in B-cell lymphoma with IgM antibodies against glycolipid GD1b. Neurol Sci 26: 355-357.

20. Obi T, Kusunoki S, Takatsu M, Mizoguchi K, Nishimura Y (1992) IgM M-protein in a patient with sensory-dominant neuropathy binds preferentially to polysialogangliosides. Acta Neurol Scand 86: 215-218.

21. Paradas C, Morgado Y, Gallardo E, Juarez C, Rojas-García R (2011) Prednisone can worsen ataxic neuropathy with anti-disialosyl IgM antibodies. Muscle Nerve 44: 839-841.

22. Rojas-Garcia R, Gallardo E, Povedano M, de Luna N, Bruna J, et al. (2008) Antibodies against disialosyl and terminal NeuNAc(alpha2-3)Gal ganglioside epitopes in acute relapsing sensory ataxic neuropathy. J Neurol 255: 764-766.

23. Sanvito L, Rajabally YA (2011) Optic neuropathy associated with CANOMAD: description of 2 cases. Muscle Nerve 44: 451-455.

24. Siddiqui K, Cahalane E, Keogan M, Hardiman O (2003) Chronic ataxic neuropathy with cold agglutinins: atypical phenotype and response to anti-CD20 antibodies. Neurology 61: 1307-1308.

25. Susuki K, Yuki N, Hirata K (2001) Features of sensory ataxic neuropathy associated with anti-GD1b IgM antibody. J Neuroimmunol 112: 181-187.

26. Taguchi Y, Takashima S, Kusunoki S, Asaoka E, Inoue H (2003) Chronic sensory ataxic neuropathy with polyclonal IgM reactivity to various disialosyl gangliosides. Muscle Nerve 28: 128-129.

27. Umehara F, Kore-Eda Y, Arime T, Kubota R, Arimura K, et al. (1997) Chronic sensory ataxic neuropathy and ophthalmoplegia with oculomotor nerve hypertrophy associated with IgM antibodies against gangliosides containing disialosyl groups. J NeurolNeurosurg Psychiatry 62: 673-674.

28. Villa AM, López PH, Sevlever G, Nores GA, Sica RE (2002) Antiganglioside antibodies in serum of patients with chronic sensory ataxic neuropathy. Medicina (B Aires) 62: 237-240. 